\title{
O SERVIÇO DE REFERÊNCIA VIRTUAL EM BIBLIOTECAS NACIONAIS E INTERNACIONAIS: UM ESTUDO COMPARATIVO
}

\author{
Vitor Vasata Macchi Silva \\ Mestre em Engenharia de Produção \\ . Bacharel em Engenharia de Produção e em Biblioteconomia (UFRGS). \\ http://orcid.org/0000-0001-8921-9727 \\ vasata@hotmail.com
}

\section{Resumo}

\begin{abstract}
Apresenta um estudo cujo objetivo é identificar os elementos que caracterizam os serviços de referência virtual ofertados por bibliotecas nacionais e internacionais. Aponta as diferenças existentes entre os termos "biblioteca eletrônica", "biblioteca digital" e "biblioteca virtual". Destaca que foram analisados os serviços de referência virtual ofertados por cinco bibliotecas: a (i) Biblioteca Nacional de España; a (ii) Bibliothèque nationale de France; a (iii) University of Illinois at Chicago Library; a (iv) Biblioteca Nacional do Brasil; e a (v) Biblioteca de Ciências Jurídicas da Universidade Federal do Paraná. Retrata, a partir de um quadro comparativo, que todas as bibliotecas analisadas ofertam serviços de referência virtual que operam em modo assíncrono. Ressalta que apenas duas ofertam tais serviços em modo síncrono. Destaca que as bibliotecas brasileiras analisadas requerem uma série de informações a respeito de seus usuários. Conclui que "sincronicidade", "prazo para resposta" e "informações dos usuários" são os elementos-chave a serem observados por bibliotecas que pretendem ofertar serviços de referência virtual.
\end{abstract}

Palavras-chave: Serviços de biblioteca. Serviços de referência. Bibliotecas virtuais. Usuários.

\section{INTRODUÇÃO}

As bibliotecas virtuais são sistemas de informação em rede que oferecem a seus usuários conteúdos e serviços digitais cuja informação e meios de comunicação se encontram em servidores distribuídos em diferentes partes do mundo (TORRES VARGAS; SÁNCHEZ AVILLANEDA, 2005). Assim, neste tipo de biblioteca, considera-se que os serviços são resultado do manejo da informação digital através de tecnologias de comunicação e informação. Tal característica confere, segundo Torres Vargas e Sánchez Avillaneda (2005), aos serviços desse tipo de biblioteca, características distintas às dos serviços oferecidos em bibliotecas convencionais.

Entre os serviços oferecidos nas bibliotecas virtuais encontra-se o serviço de referência virtual. Destaca-se, neste âmbito, que o serviço de referência serve como um mediador entre o conhecimento disponibilizado e o usuário que fará uso desse conhecimento (JESUS; CUNHA, 2012). Isso ocorre, segundo Jesus e Cunha (2012), pois, sem a participação desse mediador, dificilmente a informação recebida pelo usuário seria eficiente ou de qualidade. $\mathrm{O}$ serviço de referência virtual, neste cenário, segundo a American Library Association (ALA) (2004), se caracteriza por ser um serviço de referência iniciado eletronicamente, muitas vezes em tempo real, onde os usuários utilizam computadores ou outra tecnologia de Internet para entrar em contato com o setor de referência das bibliotecas.

Quanto às características do serviço de referência virtual, Pessoa e Cunha (2007) destacam que esse tipo de serviço pode ser realizado a partir da utilização de diversas ferramentas de comunicação, como correio eletrônico (e-mail), formulários via Web, videoconferência, chat e softwares "Real-time Live Web Reference". De modo complementar, a ALA (2004) destaca que esse tipo de serviço pode ser acompanhado de atendimentos via telefone, fax e correio normal, mesmo que esses modos de comunicação não sejam considerados virtuais.

Com relação ao tempo de resposta para as demandas recebidas pelos setores de 
referência, Siqueira (2010), destaca que os serviços de referência virtual podem ser categorizados em síncronos e assíncronos. Neste âmbito, essa autora destaca que, nos serviços síncronos, o bibliotecário responde instantaneamente às demandas dos usuários; nos serviços assíncronos, de modo distinto, as respostas dos bibliotecários podem demorar dias para serem entregues. Assim, são exemplos de atendimentos síncronos aqueles atendimentos que ocorrem via chat; e de atendimentos assíncronos aqueles atendimentos que ocorrem via e-mail e formulários (SIQUEIRA, 2010).

No contexto do serviço de referência virtual, o usuário remoto corresponde àquele usuário que tem acesso aos serviços de uma biblioteca sem realmente entrar fisicamente nesta biblioteca (DEBOWSKI, 2003). Neste cenário, segundo Debowski (2003), a aproximação a esses usuários se justifica quando se observa que a natureza dos usuários de uma biblioteca está sofrendo mudanças notáveis e que a forma de atender a esses novos usuários é distinta daquela que é tradicionalmente realizada em bibliotecas físicas. A partir disto, essa autora destaca que as bibliotecas devem começar a redesenhar a forma de proporcionar novos serviços aos novos usuários, visto que a relação com o usuário local é distinta, uma vez que se caracteriza por ocorrer de forma totalmente direta.

A partir dos aspectos citados, aponta-se que o objetivo geral deste trabalho é identificar elementos que caracterizam os serviços de referência virtual ofertados a usuários remotos por bibliotecas nacionais e internacionais. Os objetivos específicos, por sua vez, são identificar os modelos de atendimento ofertados (síncronos ou assíncronos) e, também, as informações solicitadas aos usuários para que os serviços sejam realizados. Considera-se, neste cenário, que o mapeamento dos serviços ofertados por essas bibliotecas pode ser valioso para aquelas que ainda não disponibilizam esse tipo de serviço e que pretendem identificar qual tipo de serviço pode melhor se adequar ao seu contexto.

As próximas seções apresentam: (i) o referencial teórico que apresenta os conceitos abordados no estudo; (ii) os procedimentos metodológicos adotados para atingimento dos objetivos propostos; (iii) os resultados e as conclusões do trabalho desenvolvido; e (iv) as considerações finais sobre o estudo realizado.

\section{BIBLIOTECAS VIRTUAIS: CARACTERÍSTICAS PRINCIPAIS}

As expressões "biblioteca eletrônica", "biblioteca digital" e "biblioteca virtual" têm sido utilizadas em muitas ocasiões como sinônimo na bibliografia da área (TRAMULLAS SÁZ, 2002). No entanto, tais termos possuem diferentes significados (SAYÃO, 2009). Neste cenário, a fim de evitar que tais expressões sejam utilizadas de modo equivocado, são apresentadas, no Quadro 1, definições que distinguem esses três termos.

Quadro 1 - Conceituações preliminares sobre tipos de bibliotecas

\begin{tabular}{|ll|}
\hline \multicolumn{1}{|c|}{ Termo } & \multicolumn{1}{c|}{ Conceituação preliminar } \\
\hline Biblioteca eletrônica & $\begin{array}{l}\text { Biblioteca em que há ampla utilização de computadores e de suas facilidades } \\
\text { para a construção de índices on-line, para a busca de textos completos e para a } \\
\text { recuperação e armazenagem de registros (MARCHIORI, 1997). }\end{array}$ \\
\hline Biblioteca digital & $\begin{array}{l}\text { Nesse tipo de biblioteca a informação é disponibilizada apenas na forma digital } \\
\text { e pode residir em meios de armazenagem como discos magnéticos e óticos } \\
\text { (MARCHIORI, 1997). }\end{array}$ \\
\hline Biblioteca virtual & $\begin{array}{l}\text { Biblioteca que, para existir, depende da tecnologia da realidade virtual. Assim, } \\
\text { através de um software próprio acoplado a um computador, usando uma } \\
\text { tecnologia sofisticada, é feita a reprodução virtual do ambiente de uma } \\
\text { biblioteca convencional (SILVA; ARAUJO, 2003). }\end{array}$ \\
\hline
\end{tabular}

Fonte: Elaborado pelo autor (2017)

O Quadro 1 evidencia que as bibliotecas eletrônicas referem-se àquelas bibliotecas criadas com o auxílio de sistemas utilizados para operacionalizar processos básicos, como o processo de busca de textos completos. As bibliotecas digitais, por sua vez, referem-se àquelas bibliotecas que disponibilizam informações apenas na forma digital e as bibliotecas virtuais, de modo distinto, podem 
ser vistas como reproduções virtuais dos ambientes das bibliotecas convencionais.

Quanto à oferta de produtos e serviços em bibliotecas virtuais, Paiva et al. (2011) destacam que essas unidades estão se adequando e diversificando seus produtos e serviços, como forma de apresentar um diferencial para seus usuários e, também, de atender às suas demandas. Entre os serviços que podem ser oferecidos nessas bibliotecas, Pérez et al. [200-] destacam os seguintes: (i) o serviço de seleção seletiva da informação, que seleciona informação e documentação de acordo com o perfil temático definido pelo próprio usuário; (ii) o serviço de notícias, capaz de compilar informações sobre um tema específico; (iii) o serviço de publicações oficiais e; o (iv) serviço de diários econômicos.

O serviço de referência corresponde a outro serviço que pode ser ofertado em bibliotecas virtuais. Tal serviço corresponde a uma atividade essencialmente humana, que atende a uma das necessidades mais profundamente arraigada da espécie que é o desejo de conhecer e compreender (GROGAN, 2001). Grogan (2001), neste âmbito, destaca ainda que, em buscas cujos itens são conhecidos, até uma quarta parte dos usuários não consegue encontrar o que estão procurando no catálogo da biblioteca, mesmo quando esta possui o material e este está representado no catálogo. A partir disto, esse autor ressalta o status ímpar deste serviço e o destaca como o serviço mais humano da biblioteca, uma vez que envolve uma relação direta entre o bibliotecário e o consulente.

O serviço de referência virtual, segundo a Reference and User Services Association (RUSA) (2010), se caracteriza por ser um serviço iniciado eletronicamente onde os usuários utilizam computadores ou outras tecnologias para se comunicar com os centros de informação. Neste cenário, segundo a RUSA (2010), os canais de comunicação utilizados com frequência em referência virtual são: chat; videoconferência; conavegação; e-mail; e mensagens instantâneas.

$\mathrm{O}$ usuário remoto corresponde a quem utiliza a biblioteca digital disponível online (BLATTMANN; BOMFÁ, 2006). Garcez e Rados (2002), neste âmbito, observam que os usuários remotos geralmente correspondem a pesquisadores e profissionais liberais que não necessariamente possuem vinculação com a instituição provedora e que entram em contato virtualmente. Cuenca et al. (2003), de modo complementar, destacam que a característica principal do usuário remoto é a utilização à distância das facilidades que dispõe para obtenção da informação.

De modo assertivo, Levacov, em 1997, já apontava que, com a possibilidade de acessar bibliotecas, centros de informação e bancos de dados a partir de redes de telecomunicação, os usuários remotos já não seriam mais um diminuto segmento do grande grupo de usuários. Ao contrário, pois, segundo essa autora, cada vez mais deve diminuir o número daqueles que fazem o acesso real em comparação aos que fazem o acesso virtual. Nesse cenário, compreende-se que a gestão da biblioteca virtual deve abranger aspectos como a administração de recursos materiais e humanos, a garantia de acesso, a capacitação de equipe, o gerenciamento de fluxos e, principalmente, a sua sustentabilidade ao longo do tempo (CUENCA et al., 2009).

A partir dos aspectos apresentados, podese compreender que o serviço de referência corresponde a uma realidade no âmbito das bibliotecas virtuais. Neste cenário, considerase que investigar como esse serviço tem sido ofertado em bibliotecas nacionais e internacionais corresponde a uma atividade que pode contribuir para o planejamento e a oferta de serviços desse tipo.

\section{PROCEDIMENTOS METODOLÓGICOS}

Esta pesquisa é considerada uma pesquisa aplicada, pois, conforme aponta Gil (2010), as pesquisas aplicadas são voltadas à aquisição de conhecimentos com vista à aplicação em uma situação específica. Nesse cenário, considerase que os resultados dessa pesquisa devem contribuir para o planejamento e a implantação de serviços de referência em bibliotecas virtuais. Além disto, este estudo é considerado exploratório, pois têm como propósito proporcionar maior familiaridade com $\mathrm{o}$ problema, na medida em que visa evidenciar os elementos-chave que devem ser considerados por bibliotecas que planejam ofertar tais serviços de referência.

Destaca-se, ainda quanto ao método de pesquisa utilizado neste estudo, que este utiliza dados de natureza qualitativa para a análise dos 
serviços de referência ofertados pelas Bibliotecas analisadas. Tais dados, por sua vez, foram utilizados por possuir, como benefício, o fato de considerar detalhes do contexto em que se encontram tais serviços. Além disto, destaca-se que esse trabalho corresponde a um estudo de caso, visto que busca o estudo profundo e exaustivo de um ou poucos objetos, de maneira a permitir seu amplo e detalhado conhecimento (GIL, 2010).

Quanto ao método de trabalho adotado, destaca-se que esse foi dividido em duas etapas. $\mathrm{Na}$ primeira, foram selecionadas bibliotecas brasileiras e internacionais que ofertam serviços de referência virtual. Neste âmbito, cabe destacar que os critérios utilizados para a seleção da amostra foram a tipologia das bibliotecas (nacionais ou universitárias) e a facilidade de acesso aos portais desses centros de informação. Destacase ainda que, para possibilitar a comparação dos serviços oferecidos, o objetivo foi selecionar três bibliotecas internacionais e, ao menos, duas brasileiras, sendo uma nacional e uma universitária.

$\mathrm{Na}$ segunda fase do método de trabalho foram analisadas as características dos serviços ofertados pelas bibliotecas selecionadas. Neste âmbito, destaca-se que foram caracterizados os seguintes aspectos: tipo de biblioteca, serviços ofertados, tipo de atendimento (síncrono ou assíncrono), informações solicitadas e prazo para resposta.

\section{RESULTADOS E CONCLUSÕES}

A partir dos critérios utilizados para a seleção da amostra deste estudo foram escolhidas cinco bibliotecas. Foram elas: a $(i)$ Biblioteca Nacional de España (BNE); a (ii)
Bibliothèque nationale de France (BnF); a (iii) University of Illinois at Chicago Library; a (iv) Biblioteca Nacional do Brasil (BN); e a $(v)$ Biblioteca da Universidade Federal do Paraná (UFPR). Tais bibliotecas foram escolhidas por oferecer distintos tipos de serviço de referência virtual e, também, por atender a distintos tipos de usuários. Além disto, destaca-se que todas as consultas aos portais das bibliotecas foram realizadas no dia 13 de Março de 2017. Após o mapeamento dos serviços oferecidos por essas Bibliotecas, foi elaborado o quadro comparativo desses serviços.

\subsection{BIBLIOTECA NACIONAL DE ESPAÑA}

Ao visualizar a página dos serviços ofertados pela $\mathrm{BNE}^{1}$, pode-se observar que a biblioteca classificou os serviços ofertados em quatro categorias: (i) nuevos usuarios, categoria que apresenta informações básicas relacionadas ao funcionamento da biblioteca; (ii) consulta de fondos, a qual se caracteriza por disponibilizar informações sobre como consultar o acervo da biblioteca; (iii) información bibliográfica, a qual se caracteriza por apresentar os meios que os usuários podem utilizar para realizar suas consultas; e (iv) otros servicios, a qual se caracteriza por destacar os demais serviços ofertados pela biblioteca.

A partir do acesso à opção información bibliográfica, o usuário é redirecionado para a página de consulta disponibilizada pela biblioteca. Tal página se caracteriza por apresentar um formulário que o usuário deve preencher para apresentar sua dúvida informacional. A Figura 1 apresenta a página disponibilizada pela Biblioteca.

\footnotetext{
${ }^{1}$ Disponível em: http://www.bne.es/es/Inicio/
} 
Figura 1 - Serviço de referência virtual ofertado pela Biblioteca Nacional de España

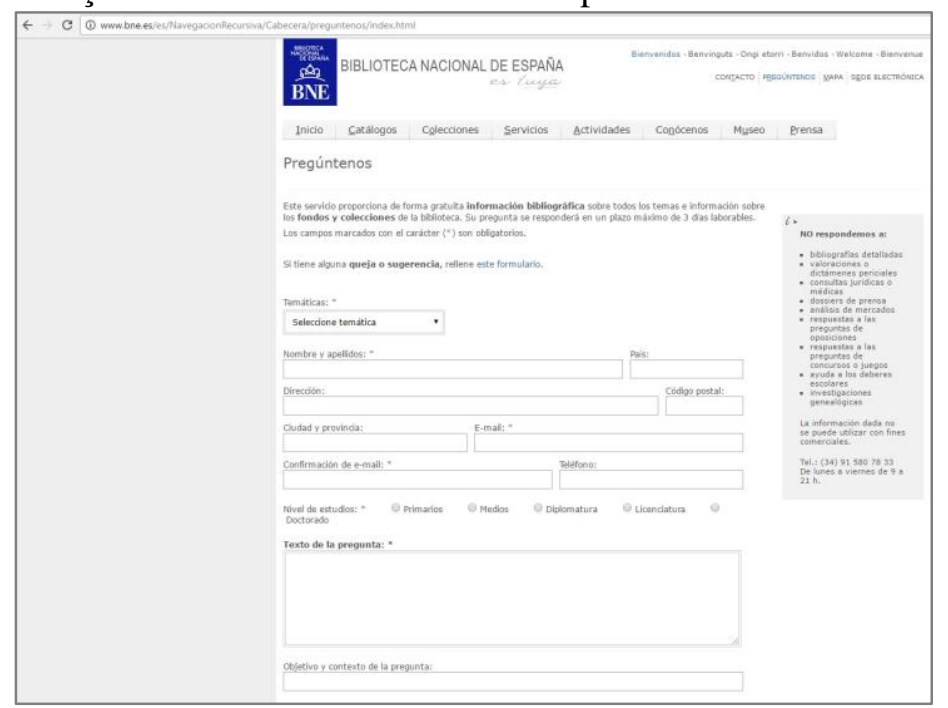

Fonte: Biblioteca Nacional de España (2017)

A partir da observação da Figura 1 pode-se observar que a BNE caracteriza-se por oferecer um serviço de referência virtual assíncrono, o qual se caracteriza por responder em até três dias úteis às demandas dos usuários. Quanto aos campos obrigatórios para realização de tal serviço, destaca-se que esses são: temática do assunto de pesquisa, nome, email e texto da pergunta. Além destes aspectos, destaca-se que a Biblioteca ressalta os tipos de questões aos quais não pode oferecer resposta. Entre esses tipos destacam-se as consultas jurídicas e médicas, as análises de mercado e as respostas às perguntas de concursos e jogos.

\subsection{BIBLIOTHÈQUE NATIONALE DE FRANCE}

Ao visualizar a página em que se pode fazer uma questão a um bibliotecário disponibilizada pela $\mathrm{BnF}^{2}$, chamada votre question, pode-se observar que a Biblioteca disponibiliza dois tipos de serviço de consultas. A Figura 2 apresenta a página disponibilizada pela Biblioteca.

Figura 2 - Serviço de referência virtual ofertado pela Bibliothèque Nationale de France

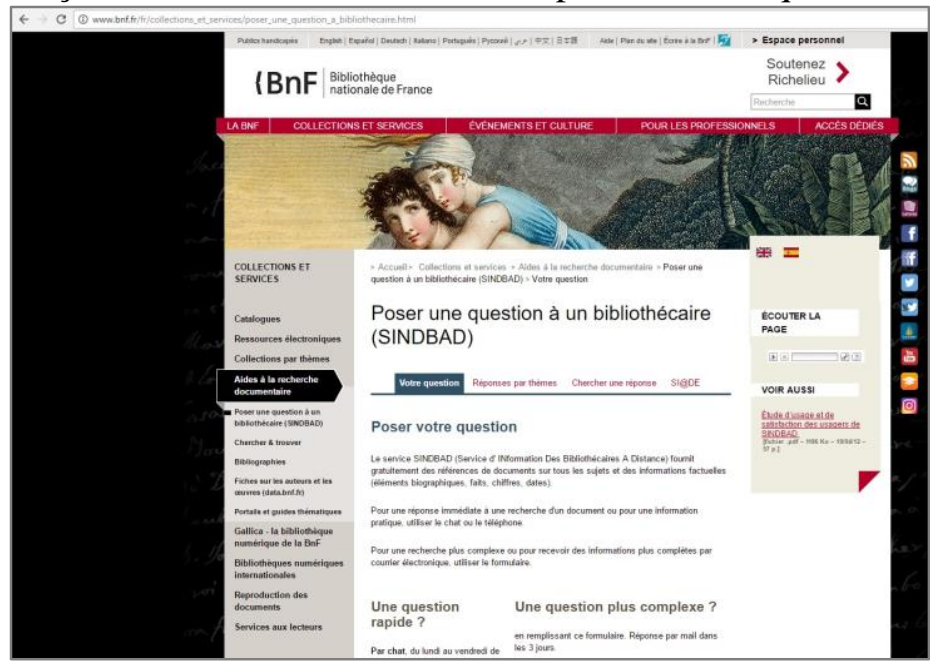

Fonte: Bibliotèque Nationale de France (2017)

\footnotetext{
${ }^{2}$ Disponível em:

http://www.bnf.fr/fr/acc/x.accueil.html
} 
A partir da análise da Figura 2, e das demais informações disponibilizadas pela $\mathrm{BnF}$ nessa página, pode-se observar que o primeiro tipo de serviço ofertado pela Biblioteca corresponde a um chat online, o qual está disponível de segunda à sexta-feira das $13 \mathrm{~h}$ às $17 \mathrm{~h}$, e que pode ser utilizado pelos usuários para realizar perguntas rápidas. Além disto, é destacado que tais perguntas também podem ser respondidas por telefone, de segunda à sexta-feira das $10 \mathrm{~h}$ às $13 \mathrm{~h}$. O segundo tipo de serviço, por sua vez, corresponde a um formulário que deve ser preenchido pelos usuários quando estes considerarem que suas dúvidas informacionais correspondem a questões complexas.

A partir das informações destacadas na página da $\mathrm{BnF}$, pode-se observar que esta oferta serviço de referência virtual síncrono e, também, assíncrono, o qual pode requerer até três dias para ser respondido. Além disto, destaca-se que a Biblioteca possibilita que os usuários busquem respostas de questões já respondidas por tópico e, também, a partir da inserção de um assunto específico em um campo de busca.

\subsection{UNIVERSITY OF ILLINOIS AT CHICAGO LIBRARY}

Ao visualizar a página contact us disponibilizada pela $\mathrm{UI}^{3}$ podem ser observadas todas as formas que podem ser utilizadas para contatar um bibliotecário dessa Universidade. A Figura 3 apresenta a página disponibilizada pela Biblioteca.

Figura 3 - Serviço de referência virtual ofertado pela University of Illinois at Chicago Library

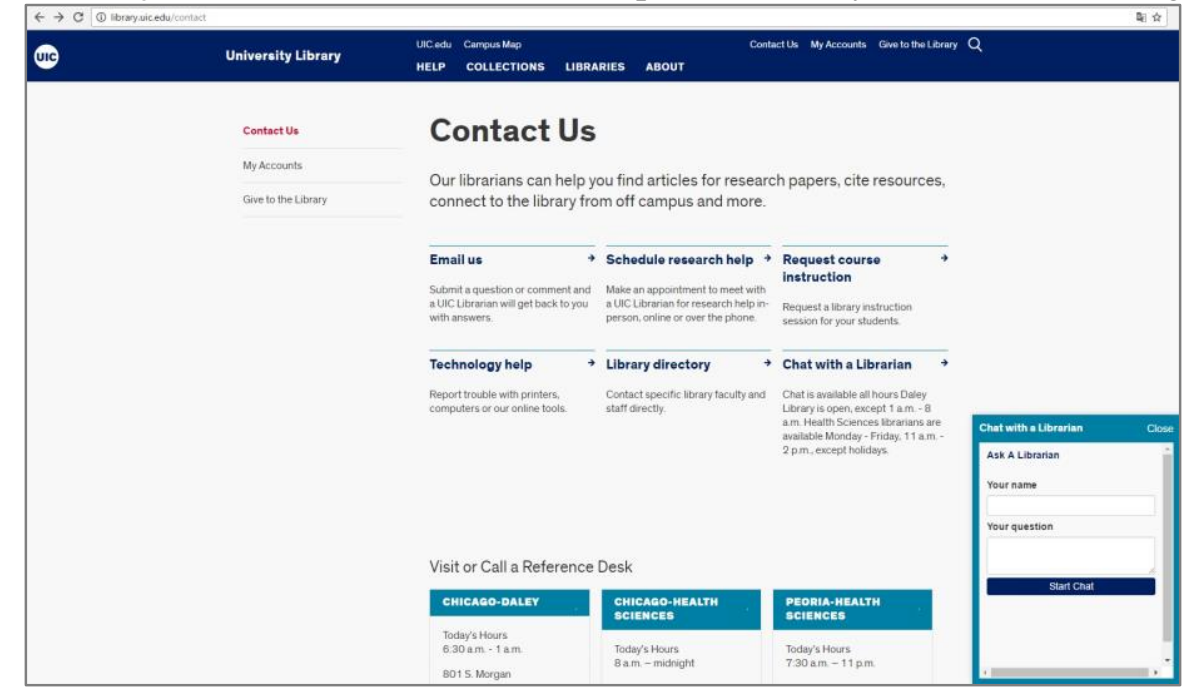

Fonte: University of Illinois at Chicago (2017)

A partir da análise da Figura 3 pode-se observar que a UI se caracteriza por oferecer o serviço de referência virtual no modo síncrono e, também, no modo assíncrono. O modo síncrono é disponibilizado através de um chat, o qual é disponibilizado em todos os horários em que a biblioteca está funcionando, com exceção do período entre $1 \mathrm{~h}$ e $8 \mathrm{~h}$. Além disto, é destacado que bibliotecários especializados na área da saúde estão disponíveis para atender aos usuários em dias e horários específicos. $\mathrm{O}$ modo assíncrono, por sua vez, é disponibilizado a partir de um link que direciona o usuário para uma página em que um formulário deve ser preenchido e encaminhado à Biblioteca. Tal formulário destaca-se por requerer o preenchimento dos campos question, more detail/explanation, name, e-mail, status (escolaridade), campus e departament.

\subsection{BIBLIOTECA NACIONAL DO BRASIL}

O serviço de referência virtual ofertado pela $\mathrm{BN}^{4}$ pode ser encontrado na opção "pesquisa à distância", disponível entre as opções de serviços disponibilizados por essa Biblioteca. A Figura 5 apresenta a página que

\footnotetext{
${ }^{4}$ Disponível em: https://www.bn.br/
}

${ }^{3}$ Disponível em: http://www.library.uic.edu 
destaca o formulário que deve ser preenchido pelo usuário.

Figura 4 - Serviço de referência virtual ofertado pela Biblioteca Nacional do Brasil

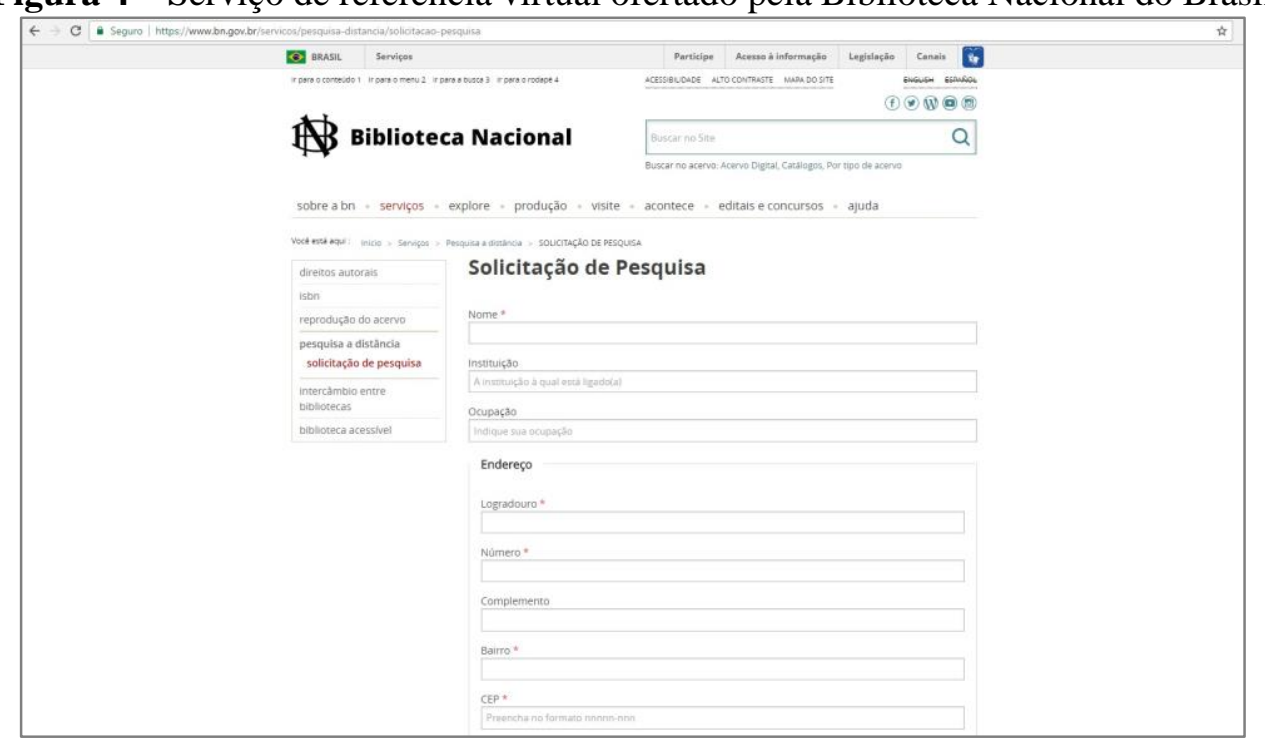

Fonte: Biblioteca Nacional do Brasil (2017)

A partir da análise da Figura 5, e das demais informações disponibilizadas pela $\mathrm{BN}$ em seu portal, pode-se observar que a $\mathrm{BN}$ disponibiliza o serviço de referência virtual apenas no modo assíncrono. Isso ocorre, pois a Biblioteca disponibiliza apenas um formulário que deve ser preenchido pelo usuário com suas dúvidas informacionais. Além disto, destacam-se dois aspectos: (i) a ausência de uma previsão de retorno para a dúvida informacional do usuário; e (ii) a grande quantidade de campos que devem ser preenchidos para que o usuário submeta seu problema de pesquisa (entre os quais logradouro, número, bairro, CEP e cidade).

\subsection{BIBLIOTECA DE CIÊNCIAS JURÍDICAS DA UNIVERSIDADE FEDERAL DO PARANÁ}

Ao visualizar a página "pesquisa bibliográfica" disponibilizada pela Universidade Federal do Paraná (UFPR) ${ }^{5}$ pode-se observar que esta apresenta a lista de bibliotecas que compõem o sistema da Universidade e, também, a recomendação de que o usuário deve verificar a disponibilidade deste serviço em cada biblioteca do Sistema. A Figura 6 apresenta a página que destaca as informações sobre os serviços de pesquisa ofertados pela Universidade.

\footnotetext{
${ }^{5}$ Disponível em:

http://www.portal.ufpr.br/index.html
} 
Figura 5 - Serviço de referência virtual ofertado pela Universidade Federal do Paraná (UFPR)

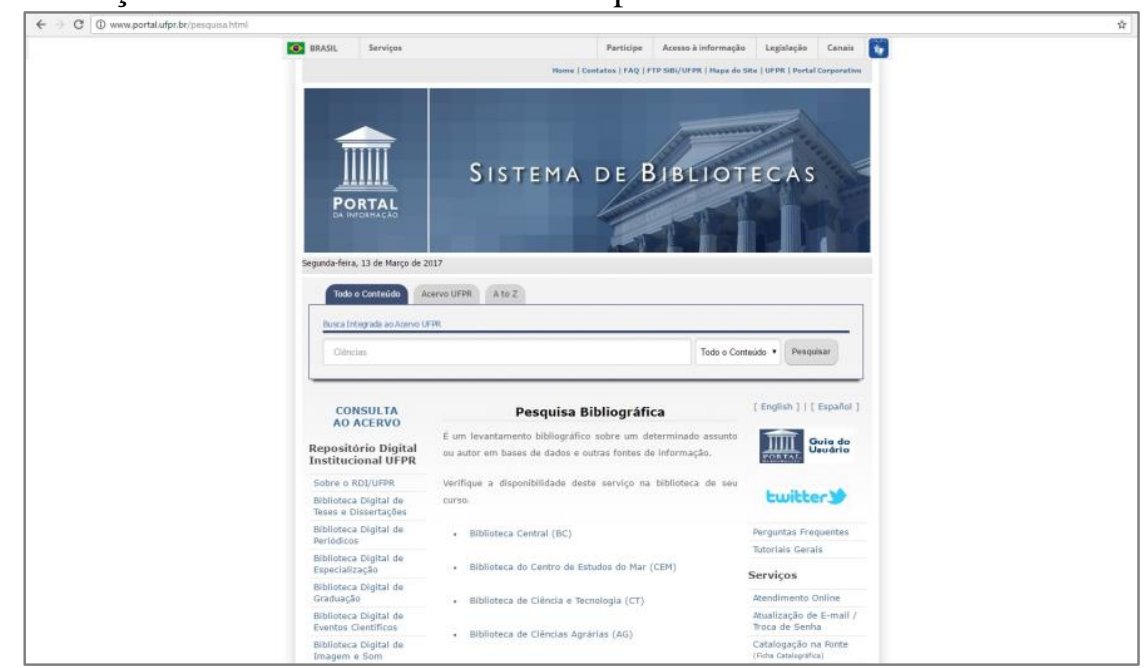

Fonte: Universidade Federal do Paraná (2017a)

A partir da análise da Figura 6, e das demais informações disponibilizadas pelo Sistema de Bibliotecas da UFPR, pode-se observar que a maioria das bibliotecas setoriais deve ser contata por e-mail ou por telefone para que sejam verificados os procedimentos necessários para a execução do serviço de pesquisa bibliográfica. Cabe destacar, neste âmbito, que duas bibliotecas disponibilizam formulários eletrônicos que podem ser preenchidos com as demandas informacionais dos usuários, a Biblioteca de Ciências Jurídicas e a Biblioteca de Artes, Comunicação e Design. Ao selecionar tais formulários, é apresentado ao usuário um link que, ao ser clicado, disponibiliza um documento em formato word para download. A figura 7 apresenta o documento apresentado aos usuários. 
Figura 6 - Formulário eletrônico disponibilizado pela Biblioteca de Ciências Jurídicas da UFPR

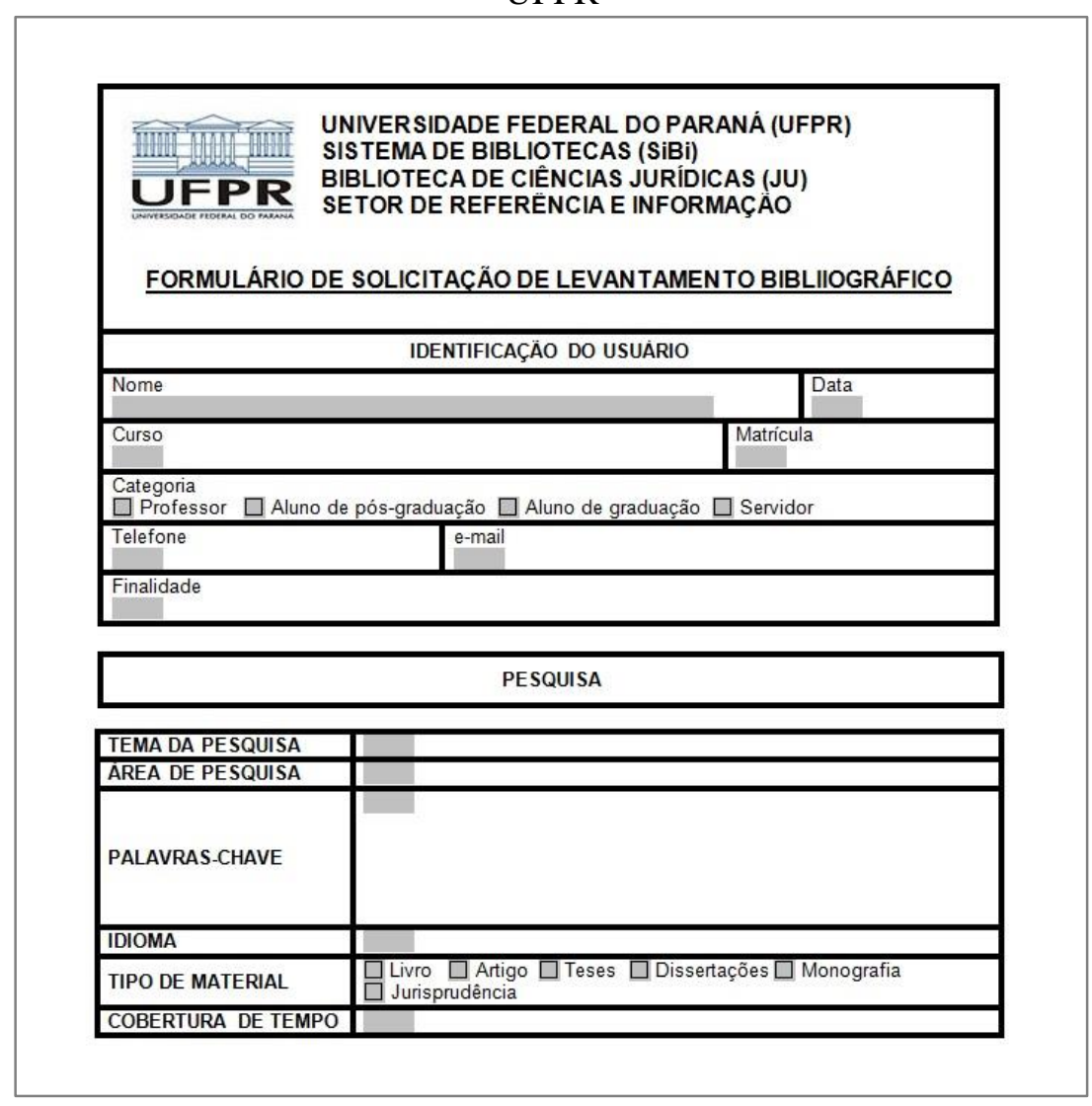

Fonte: Universidade Federal do Paraná (2017b)

A partir da análise da Figura 7 pode-se perceber que esse serviço se caracteriza como um serviço assíncrono. Isso ocorre, pois o usuário deve preencher as características de suas demandas informacionais e enviar tal documento por e-mail ou, então, entregá-lo no balcão de referência da Biblioteca. Além disto, destaca-se que não é indicado no portal do sistema de bibliotecas, ou no documento, o tempo estimado de resposta para as demandas dos usuários.

\subsection{ANÁLISE COMPARATIVA DOS SERVIÇOS DE REFERÊNCIA}

A partir dos aspectos identificados nas subseções anteriores foi construído o Quadro 2, o qual resume o serviço de referência virtual ofertado pelas bibliotecas investigadas

Quadro 2 - Resumo das características dos serviços de referência ofertados nas bibliotecas

\begin{tabular}{|l|ccccc|}
\cline { 2 - 6 } & $\begin{array}{l}\text { Biblioteca } \\
\text { Nacional de } \\
\text { España } \\
(\text { BNE })\end{array}$ & $\begin{array}{l}\text { Bibliothèque } \\
\text { nationale de } \\
\text { France }(\text { BnF })\end{array}$ & $\begin{array}{l}\text { University of } \\
\text { Illinois at } \\
\text { Chicago } \\
\text { Library }(\text { UI) }\end{array}$ & $\begin{array}{l}\text { Biblioteca } \\
\text { Nacional do } \\
\text { Brasil }(\text { BN })\end{array}$ & $\begin{array}{l}\text { Biblioteca da } \\
\text { Universidade } \\
\text { Federal do } \\
\text { Paraná }\end{array}$ \\
\hline $\begin{array}{l}\text { Tipo de } \\
\text { biblioteca }\end{array}$ & Nacional & Nacional & Universitária & Nacional & Universitária \\
\hline $\begin{array}{l}\text { Serviços } \\
\text { ofertados } \\
\text { para consultas } \\
\text { à distância }\end{array}$ & $\begin{array}{l}\text { Formulário } \\
\text { eletrônico }\end{array}$ & $\begin{array}{c}\text { Chat; } \\
\text { Formulário } \\
\text { eletrônico }\end{array}$ & $\begin{array}{l}\text { Chat; } \\
\text { Formulário } \\
\text { eletrônico }\end{array}$ & $\begin{array}{l}\text { Formulário } \\
\text { eletrônico }\end{array}$ & $\begin{array}{l}\text { Formulário } \\
\text { eletrônico }\end{array}$ \\
\hline $\begin{array}{l}\text { Atendimento } \\
\text { síncrono }\end{array}$ & Não & Sim & Sim & Não & Não \\
\hline
\end{tabular}


Fonte: Elaborado pelo autor (2017)

O Quadro 2 evidencia que os serviços de referência virtual ofertados pelas Bibliotecas analisadas apresentam características distintas. Neste âmbito, destaca-se que apenas duas das bibliotecas avaliadas, a Bibliothèque nationale de France e a University of Illinois at Chicago Library, ofertam serviços de referência virtual que operam de modo síncrono. Destaca-se, no entanto, que todas as bibliotecas avaliadas disponibilizam serviços de referência virtual que operam de modo assíncrono.

Quanto aos serviços ofertados de modo assíncrono, destaca-se que apenas duas bibliotecas determinam o tempo previsto para resposta às demandas dos usuários. Tal aspecto pode ser revisto pelas bibliotecas que não informam tal prazo. Isso se justifica, pois a previsão para resposta pode ser um critério decisivo para que os usuários efetivamente utilizem o serviço de referência virtual. Além deste aspecto, também pode ser destacado que as bibliotecas exigem diferentes informações dos usuários para a realização das pesquisas. Neste cenário, observa-se que as bibliotecas nacionais se mostram exigentes, visto que exigem informações específicas sobre os usuários. Tal característica pode ser repensada, para que o serviço de referência virtual possa passar a ser visto como um serviço acessível e ágil.

A natureza distinta dos serviços ofertados pelas bibliotecas analisadas pode ser justificada, se considerado que as bibliotecas mantêm acervos e atendem a usuários distintos. No entanto, se consideradas as necessidades informacionais dos usuários, as quais são cada vez mais urgentes, e também as tecnologias de informação disponíveis para a utilização das bibliotecas, as quais são cada vez mais numerosas, conclui-se que o serviço de referência virtual, especialmente o que ocorre de modo síncrono, corresponde a um serviço relativamente fácil de ser implantado. Entretanto, o que se observa é que as bibliotecas, principalmente as brasileiras, ainda estão se adaptando a essa realidade virtual.

Diversos podem ser os motivos que levam às bibliotecas a não disponibilizar o serviço de referência virtual síncrono. $\mathrm{O}$ excesso de atividades e a escassez de recursos humanos capacitados para lidar com as tecnologias de informação e comunicação podem ser alguns dos fatores que influenciam na composição deste cenário. Além disto, a escassez de recursos financeiros, a qual impacta diretamente o processo de aquisição de tecnologias, também pode ser considerada como motivo. Estabelece-se, a partir dos aspectos destacados, um cenário no qual as bibliotecas devem procurar alternativas para captar recursos financeiros para investir em seus recursos humanos e tecnológicos.

\section{CONSIDERAÇÕES FINAIS}

O objetivo desse trabalho foi identificar os elementos que caracterizam o serviço de referência virtual ofertado por bibliotecas nacionais e internacionais. A partir disto, 
foram selecionadas cinco bibliotecas, sendo três internacionais e duas nacionais, para que fossem identificadas as características dos serviços de referência ofertados por cada uma dessas unidades de informação.

A pesquisa realizada indicou que todas as bibliotecas analisadas disponibilizam o serviço de referência virtual em que o atendimento ocorre de modo assíncrono e que apenas duas disponibilizam o serviço em que o atendimento ocorre de modo síncrono. Além disto, foi destacado que apenas duas bibliotecas determinam o tempo previsto para resposta às demandas dos usuários e, também, que as bibliotecas nacionais caracterizam-se por exigir informações detalhadas sobre os usuários. A partir dos casos analisados, foi considerado que "sincronicidade", "prazo para resposta" e "informações dos usuários" são os elementos-chave a serem observados por bibliotecas que planejam ofertar serviços de referência virtual.

Como conclusão, a pesquisa destacou que, se consideradas as necessidades informacionais dos usuários e, também, as tecnologias de informação disponíveis para a utilização das bibliotecas, o serviço de referência virtual, especialmente o que ocorre de modo síncrono, corresponde a um serviço relativamente fácil de ser implantado. Cabe, desta forma, às bibliotecas, procurarem alternativas para captar recursos financeiros para investir em seus recursos humanos e tecnológicos. Tal busca se justifica para que esses possam, assim, atender às demandas informacionais dos usuários, as quais estão ligadas a aspectos como agilidade e precisão.

O serviço de referência corresponde a uma atividade elementar e que não deve deixar de ser ofertada, em função da importância que assume para os usuários de unidades de informação. Tal aspecto contribui para a inferência de que distintos estudos podem ser desenvolvidos nesse tema, visto que podem ser observadas as diferentes relações que são estabelecidas entre usuários, bibliotecários e tecnologias. Neste âmbito, sugere-se a investigação da transcrição dos atendimentos aos usuários que ocorrem de modo síncrono e assíncrono. Como resultado, espera-se que sejam identificadas as principais demandas dos usuários de serviços de referência virtual e seja direcionado o treinamento dos recursos humanos necessários para a execução desses serviços. Complementarmente, também se pode validar o estudo de Schiller (2016), que indica que a medição de aprendizagem assume papel de destaque em atendimentos à distância.

Artigo recebido em: 16/03/2017

Aceitacão definitiva em: 22/05/2017

THE VIRTUAL REFERENCE SERVICE IN BRAZILIAN AND INTERNATIONALS LIBRARIES: A COMPARATIVE STUDY

\begin{abstract}
Present a study that aims to identify the aspects that characterize the virtual reference services offered by Brazilian and internationals libraries. Point the differences that existent between "electronic library", "digital library" and "virtual library" terms. Highlight that was analyzed the virtual reference services offered by five libraries: the (i) Spanish National Library; the (ii) French National Library; the (iii) University of Illinois at Chicago Library; the (iv) Brazilian National Library; and the (v) Juridical Sciences Library of the Federal University of Paraná. Understands, from a comparative table, that all analyzed libraries offers asynchronous virtual references services. Highlight that only two analyzed libraries offer this services in a synchronous mode. Underline that Brazilian analyzed libraries require
\end{abstract}


a range of information about theirs users. Conclude that "synchronicity", "deadline for response" and "user information" are the key elements to be observed by libraries that pretend to offer virtual reference services.

Keywords: Library and archival services. Reference services. Virtual libraries. Users.

\section{REFERÊNCIAS}

AMERICAN LIBRARY ASSOCIATION -

ALA. Reference and user services association. Guidelines for implementing and maintaining virtual reference services. 2004. Disponível em:

$<$ http://www.ala.org/rusa/resources/guidelines /virtrefguidelines >. Acesso em: 02 Mar. 2017.

BIBLIOTECA NACIONAL DE ESPAÑA BNE. Servicios. Pregúntenos. 2017.

Disponível em:

$<$ http://www.bne.es/es/NavegacionRecursiva/ Cabecera/preguntenos/index.html>. Acesso em: 13 Mar. 2017.

BIBLIOTÈQUE NATIONALE DE FRANCE - BnF. Collections et services. Aides à la recherche documentaire. Poser une question à un bibliothécaire (SINDBAD). Vostre question. 2017. Disponível em:

$<$ http://www.bnf.fr/fr/collections_et_services/ poser une question a bibliothecaire/s.sindba d_votre_question.html?first_Art=oui > Acesso em: 13 Mar. 2017.

BIBLIOTECA NACIONAL DO BRASIL $\mathrm{BN}$. Serviços. Pesquisa à distância.

Solicitação de pesquisa. 2017. Disponível em: <https://www.bn.gov.br/servicos/pesquisadistancia/solicitacao-pesquisa >. Acesso em: 13 Mar. 2017.

BLATTMANN, U.; BOMFÁ, C. R. Z. Gestão de conteúdos em bibliotecas digitais: acesso aberto de periódicos científicos eletrônicos. Revista Brasileira de Biblioteconomia e Documentação, Nova Série, São Paulo, v. 2, n. 1, p. 41-56, jul./dez. 2006. Disponível em:

<http://rbbd.febab.org.br/rbbd/article/view/4/ 21>. Acesso em: 08 Mar. 2017.

CUENCA, A. M. B. et al. Biblioteca virtual e $\mathrm{o}$ acesso às informações científicas e acadêmicas. Revista USP, São Paulo, n.80, p 72-83, dez./fev. 2009. Disponível em:

<http://www.revistas.usp.br/revusp/article/vie wFile/13717/15535>. Acesso em: 08 Mar.

2017.

CUENCA, A. M. B. et al. O usuário remoto de uma biblioteca acadêmica na área de saúde pública. Informação \& Sociedade: Estudos, João Pessoa, v. 13, n. 2, p. 91-109, jul./dez., 2003. Disponível em:

$<$ http://www.ies.ufpb.br/ojs2/index.php/ies/ar ticle/view/92/1563>. Acesso em: 08 Mar. 2017.

DEBOWSKI, S. Service to remote library users. In: Encyclopedia of library and information science, $2 \mathrm{a}$ ed. Edited by Miriam A. Drake, Marcel Dekker. New York: [s. n.], 2003. p. 2626-2635.

GARCEZ, E. M. S.; RADOS, G. J. V. Biblioteca híbrida: um novo enfoque no suporte à educação a distância. Ciência da Informação, Brasília, v. 31, n. 2, p. 44-51, maio/ago. 2002. Disponível em: <http://www.scielo.br/pdf/ci/v31n2/12907.pdf >. Acesso em: 08 Mar. 2017.

\section{GIL, A. C. Como elaborar projetos de}

pesquisa. 5. ed. São Paulo: Atlas, 2010.

GROGAN, D. A prática do serviço de referência. Brasília: Briquet de Lemos / Livros, 2001.

JESUS, D. L. de; CUNHA, M. B. da. Produtos e serviços da web 2.0 no setor de referência das bibliotecas. Perspectivas em Ciência da Informação, v. 17, n. 1, p.110133, 2012. Disponível em:

$<$ http://www.scielo.br/pdf/pci/v17n1/a07v17n 1.pdf >. Acesso em: 02 Mar. 2017.

LEVACOV, M. Bibliotecas virtuais: (r) evolução? Ciência da Informação, Brasília, v. 26, n. 2, maio/ago. 1997. Disponível em: 
<http://www.scielo.br/pdf/ci/v26n2/v26n22.pdf >. Acesso em: 08 Mar. 2017.

MARCHIORI, P. Z. "Ciberteca" ou biblioteca virtual: uma perspectiva de gerenciamento de recursos de informação. Ci. Inf., Brasília, v. 26, n. 2, Maio 1997. Disponível em: http://dx.doi.org/10.1590/S010019651997000200002. Acesso em: 06 Mar. 2017.

PAIVA, M. R. et al. Produtos e serviços de acesso livre oferecidos em universidades paranaenses: foco na atuação das bibliotecas. In: Congresso Brasileiro de Biblioteconomia, Documentação e Ciência da Informação, 24., Maceió (AL), 2011. Anais... Maceió: [s. n.], 2011. Disponível em:

$<$ http://repositorio.utfpr.edu.br/jspui/handle/1/ 165>. Acesso em: 07 Mar. 2017.

PÉREZ, A. et al. Bibliotecas y centros de documentación virtuales en la nueva era de la sociedad de la información: la Biblioteca

Virtual de la UOC [online]. [200-].

Disponível em:

$<$ http://cvc.cervantes.es/ensenanza/formacion _virtual/edicion digital/perez.htm>. Acesso em: 07 Mar. 2017.

PESSOA, P.; CUNHA, M. B. da. Perspectivas dos serviços de referência digital. Inf. \& Soc.:Est., João Pessoa, v. 17, n. 3, p. 69-82, 2007. Disponível em: <http://www.ies.ufpb.br/ojs2/index.php/ies/ar ticle/view/836/1587>. Acesso em: 02 Mar. 2017.

\section{REFERENCE AND USER SERVICES} ASSOCIATION - RUSA. Guidelines for implementing and maintaining virtual reference services. 2010. Disponível em: $<$ http://www.ala.org/rusa/sites/ala.org.rusa/fil es/content/resources/guidelines/virtualreference-se.pdf>. Acesso em: 07 Mar. 2017.

SAYÃO, L. F. Afinal, o que é uma biblioteca digital? Revista USP, São Paulo, n.80, p. 617, dezembro/fevereiro 2009. Disponível em: $<$ http://www.revistas.usp.br/revusp/article/vie w/13709/15527>. Acesso em: 06 Mar. 2017.

SCHILLER, S. Z. CHAT for chat: Mediated learning in online chat virtual reference service. Computers in Human Behavior, Oxford, v. 65, p. 651-665, 2016. Disponível em:

〈https://doi.org/10.1016/j.chb.2016.06.053 >. Acesso em: 03 Maio 2017.

SILVA, D. A. da; ARAUJO, I. A. Auxiliar de bibliotecas técnicas e práticas para formação profissional. Brasília: Thesaurus, 2003.

SIQUEIRA, J. C. Repensando o serviço de referência: a possibilidade virtual.

PontodeAcesso, Salvador, v. 4, n. 2, p. 116130, 2010. Disponível em:

<http://www.portalseer.ufba.br/index.php/revi staici/article/view/4238/3408>. Acesso em: 03 Mar. 2017.

TORRES VARGAS, G. A.; SÁNCHEZ AVILLANEDA, M. del R. El servicio de referencia en la biblioteca digital.

Investigación bibliotecológica, México, v. 19, n. 39, dic. 2005. Disponível em: <http://www.scielo.org.mx/pdf/ib/v19n39/v19 n39a7.pdf >. Acesso em: 02 Mar. 2017.

TRAMULLAS SÁZ, J. Propuestas de concepto y definición de la biblioteca digital. 2002. In: JORNADAS DE BIBLIOTECAS DIGITALES - JBIDI, 3; Proceedings ... El Escorial, 2002. Disponível em: $<$ http://eprints.rclis.org/15118/1/04_2002.pdf >. Acesso em: 06 Mar. 2017.

UNIVERSIDADE FEDERAL DO PARANÁ - UFPR. Portal da informação. Pesquisa bibliográfica. 2017a. Disponível em: <http://www.portal.ufpr.br/pesquisa.html >. Acesso em: 13 Mar. 2017.

UNIVERSIDADE FEDERAL DO PARANÁ - UFPR. Sistema de Bibliotecas. Biblioteca de Ciências Jurídicas. Formulário de solicitação de levantamento bibliográfico [recurso eletrônico]. 2017b.

UNIVERSITY OF ILLINOIS AT CHICAGO LIBRARY. Contact. 2017. Disponível em: $<$ http://library.uic.edu/contact $>$. Acesso em: 13 Mar. 2017. 